\title{
Suitability of magnetic nanofluid in heat transfer loops
}

\author{
Praveena Devi N. ${ }^{*}$, Ch. Srinivasa Rao ${ }^{2}$, Kiran Kumar K. ${ }^{3}$ \\ ${ }^{1}$ S R Engineering College, Warangal 506371, Telangana, India \\ ${ }^{2}$ Andhra University, Visakhapatnam 530003, Andhra Pradesh, India \\ ${ }^{3}$ NIT Warangal506004, Telangana, India
}

Corresponding Author Email: praveenadevi@gmail.com

https://doi.org/10.18280/ijht.360126

Received: 21 September 2017

Accepted: 5 March 2018

\section{Keywords:}

heat transfer, pumping power, electronic cooling, figure of merit, magnetic field.

\begin{abstract}
The objective of this paper is to provide a simple procedure to find the suitability of magnetic nanofluid (MNF) for using it as working fluid in different cooling loops. $\mathrm{Fe}_{3} \mathrm{O}_{4} /$ water nanofluid which is one type of MNF is chosen for the study. Heat can be transferred from one place to other place by using (i) Natural Circulation Loops (in which flow is driven due to the density difference generated within the loop) (ii) Forced Circulation Loop (in which flow is driven by the external aid). Effect of using $\mathrm{Fe}_{3} \mathrm{O}_{4} /$ water nanofluid in these two different loops is evaluated quantitatively. Analytical expressions are derived for both flow configurations (FCL and NCL). The results are presented in terms of non-dimensional diameters ratio and non-dimensional temperature gradients ratio. Comparison is made between water and $\mathrm{Fe}_{3} \mathrm{O}_{4} /$ water nanofluid. It is found that $\mathrm{Fe}_{3} \mathrm{O}_{4} /$ water nanofluid based Natural Circulation Loop size is reduced by $4 \%$ at $1 \%$ nanofluid concentration and the size reduction is more at higher concentrations. In case of Forced Circulation Loop, the results are presented in terms of newly defined term called as 'figure of merit' as well as diameters ratio. Effect of external magnetic field strength on thermal conductivity is measured and empirical correlation is proposed. A separate analytical expression is derived to predict the change in the size of the heat transfer loop due to the applied magnetic field. It is to be note that, the procedure laid down in this paper is adoptable to any fluid. It is found that, by applied external magnetic field, size of loop is reduced considerably.
\end{abstract}

\section{INTRODUCTION}

Past decade witnessed rapid increase in power density levels in electronic devices. Due to the higher power densities, temperatures of the devices increase at alarming rate. Due to the limitations over air cooling and conventional heat transfer enhancement techniques, there has been increasing interest towards liquid cooling of electronic components. However, liquid cooling option suffers with its own drawbacks such as high pumping power, working fluid compatibility with chip material etc. To increase the heat transfer rate further, it is proposed to use 'nanofluid' as working fluid in cooling loops in place of conventional working fluids. Uniform suspension of nanoparticles in the base fluid increases heat transfer between solid particles and fluid particles thereby increases effective heat transfer from the heat source.

Different configurations and different methods of cooling electronic equipment have been reported by Nakayama et al [1]. State-of-the art reviews on this area are published by few researchers [2-4]. Recent studies on applications of nanofluids and its hydrothermal behaviour can be found in various research papers published by Nasrinet. al [11], Ammar Maouassi et.al. [12] and Fazle Mabood et al [13]. It is to be noted that, there are two methods of heat transportation, one by using forced circulation of working fluid (Forced Circulation Loop, FCL) and other by natural circulation (Natural Circulation Loop, NCL) of working fluid. Irrespective of the type of the cooling loop, working fluid or coolant should possess good thermo-physical properties such as low viscosity, high thermal conductivity, low friction factor, high heat capacity, etc. Unfortunately, no conventional fluids have all these properties. Hence, there is a need to look for tailor made working fluids, such as nanofluids, to be used as coolants. Among the several types of the nanofluids, magnetic nanofluids (MNF) are a special category of smart fluids which can be magnetically controllable. It is observed from the literature that, by varying magnetic field strength and magnetic field direction, heat transfer rates can be controlled.

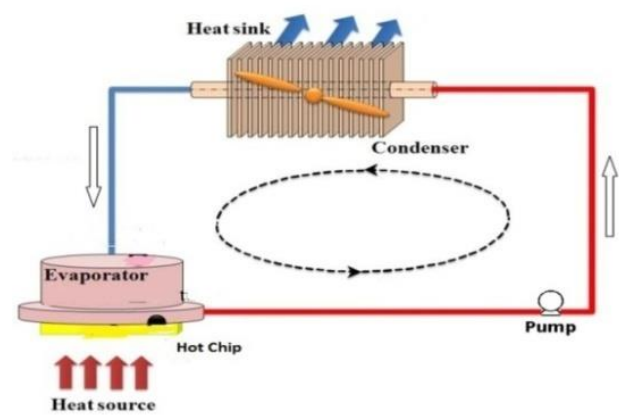

Figure 1.1 Forced Circulation Loop (FCL)

It may seem that, FCL, being more generally used, should make the NCL obsolete. However, it should be emphasized that the FCL is not reliable and incurs extra cost (due to pumping power requirement). Criteria for the selection of 
good cooling loop/working fluid should be based on the aspects such as reliability, small size, inexpensive, low temperature gradient across heat source and heat sink, compatibility to the equipment or the environment.

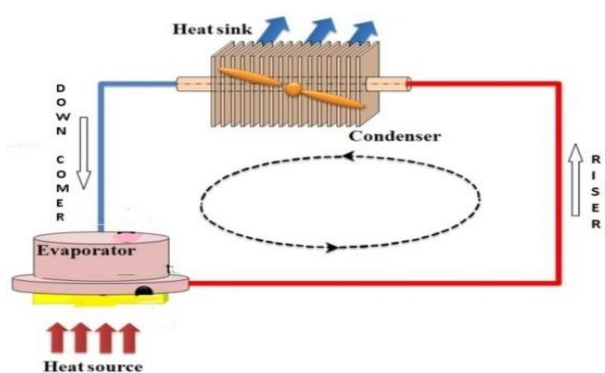

Figure 1.2 Natural Circulation Loop (NCL)

The purpose of the present paper is to discuss about the suitability of the $\mathrm{MNF}\left(\mathrm{Fe}_{3} \mathrm{O}_{4} /\right.$ water $)$ as a coolant in both NCL and FCL. The discussion is supported by results derived from closed form analytical expressions. Results also extended by proposing another analytical expression to find the effect of magnetic field strength on heat transfer loop. Schematic of FCL and NCL are shown in Figure. 1.1 and Figure. 1.2 respectively.

\section{MATHEMATICAL FORMULATION}

Mathematical formulation is presented separately for natural circulation mode and forced circulation mode of heat transfers in the subsequent sections.

\subsection{Choice of working fluid for FCL}

As mentioned in the foregoing section, minimum pumping power and minimum size are two important aspects which decide the choice of system. The pressure drop depends not only on the volume flow rate but also on the density and viscosity of the working fluid. Pressure drop can be calculated from eqn. 1 .

Pressure drop:

$\Delta p=f_{c} \rho u^{2} \frac{L}{d}$

where friction factor $\left(f_{c}\right)$ can be calculated from Blasius Correlation, given by eqn. 2 .

$$
f_{c}=0.158 \cdot \operatorname{Re}^{-0.25}
$$

Reynolds number:

$$
\operatorname{Re}=\frac{u \cdot d}{v}
$$

Velocity of working fluid is given by

$$
u=\frac{V}{A}=\frac{m}{\rho * \frac{\pi d^{2}}{4}}=\frac{Q / c \Delta T}{\rho \cdot \frac{\pi d^{2}}{4}}=\frac{4 Q}{c \Delta T \rho \pi d^{2}}
$$

By substituting eqns 2,3 and 4 in equation 1, pressure drop due to friction can be calculated by eqn. 5 .

$\Delta p=0.341 \cdot \frac{L_{t} Q^{7 / 4}}{d^{19 / 4}} \cdot \frac{1}{\Delta T^{7 / 4}} \cdot\left\{\frac{\mu^{1 / 4}}{\rho \cdot c^{7 / 4}}\right\}$

The factor in the open parenthesis is defined as 'figure of merit'. For the same heat load ' $Q$ ', loop length ' $L_{t}$ ', Diameter ' $\mathrm{d}$ ' and same temperature difference across heat sink ' $\Delta \mathrm{T}$ ', it can be seen that the figure of merit is as a function of viscosity, density and specific heat of working fluid.

Pumping power can be calculated from eqn.6. :

$P=\frac{\Delta p \cdot V}{\eta}$

Heat Transfer rate(Q) is given by eqn.7.

$Q=m c \Delta T=V \rho c \Delta T$

The volumetric heat capability of the fluid is defined as the cooling capacity divided by the volume flow rate i.e. $\mathrm{Q} / \mathrm{V}$. From eqn. 7.it can be observed that, for a fixed temperature drop across the heat source ' $\Delta \mathrm{T}$ ', volumetric flow rate is proportional to the volumetric heat capacity i.e. ' $\rho c$ '.

For the purpose of comparison between any two fluids, an analytical expression is derived in terms of the diameters ratio from equations 6,7 and 8 . For same pumping power, by keeping the heat input, temperature drop across the heat source and total loop length same, it can be shown that the ratio of the required diameter of the loop when $\mathrm{MNF}$ as working fluid to that of any other conventional fluid $\left(\mathrm{d}_{\mathrm{MNF}} / \mathrm{d}_{\mathrm{F}}\right)$ is given by:

$\frac{d_{M N F}}{d_{F}}=\left(\frac{\mu_{M N F}}{\mu_{F}}\right)^{1 / 19}\left(\frac{\rho_{F}}{\rho_{M N F}}\right)^{8 / 19}\left(\frac{c_{F}}{c_{M N F}}\right)^{11 / 19}$

\subsection{Choice of working fluid for NCL}

Under steady state conditions in the natural circulation loop, when the buoyancy and frictional forces are perfectly in balance, it can be easily shown [5] that flow rate is given by eqn.9.

$V=\left(\frac{2 \beta \Delta z P}{\rho c R}\right)^{1 / 3}$

And the temperature difference across the heat source is given by

$\Delta T=\left(\frac{P}{\rho c}\right)^{2 / 3}\left(\frac{R}{2 g \beta \Delta z}\right)^{1 / 3}$

where $\mathrm{R}$ is the overall resistance parameter defined by

$4 \frac{L_{t}}{d \cdot A^{2}} f_{c}$

By applying appropriate friction factor correlations for 
laminar flow and turbulent flow separately, Kiran Kumar et. al. [6] proposed a closed form analytical solution to compare different working fluids.

Keeping the heat input, temperature drop across the hot heat exchanger, loop height and total length same, it can be shown that the ratio of the required diameter of the loop when MNF as working fluid to that with any other conventional fluid $\left(\mathrm{d}_{\mathrm{MNF}} / \mathrm{d}_{\mathrm{F}}\right)$ is given by:

for laminar flow

$\frac{d_{M N F}}{d_{F}}=\left(\frac{\mu_{M N F}}{\mu_{F}}\right)^{1 / 4}\left(\frac{\rho_{F}}{\rho_{M N F}}\right)^{1 / 2}\left(\frac{c_{F}}{c_{M N F}}\right)^{1 / 4}\left(\frac{\beta_{F}}{\beta_{M N F}}\right)^{1 / 4}$

for turbulent flow

$\frac{d_{M N F}}{d_{F}}=\left(\frac{\mu_{M N F}}{\mu_{F}}\right)^{1 / 19}\left(\frac{\rho_{F}}{\rho_{M N F}}\right)^{8 / 19}\left(\frac{c_{F}}{c_{M N F}}\right)^{7 / 19}\left(\frac{\beta_{F}}{\beta_{M N F}}\right)^{4 / 19}$

Table 1. Thermo-physical properties of water and nanoparticles

\begin{tabular}{|c|c|c|c|c|}
\hline & $\begin{array}{c}\rho \\
\left.\mathrm{kg} / \mathrm{m}^{3}\right)\end{array}$ & $\begin{array}{c}\mathrm{c} \\
(\mathrm{kJ} / \mathrm{kgK})\end{array}$ & $\mu(\mathrm{Pa}-\mathrm{s})$ & $\beta\left(\mathrm{K}^{-1}\right)$ \\
\hline Water & 1000 & 4.187 & 0.001003 & $21^{*} 10^{-5}$ \\
\hline $\begin{array}{c}\mathrm{MNF} \\
\left(\mathrm{Fe}_{3} \mathrm{O}_{4}\right)\end{array}$ & 5180 & 0.670 & - & $0.85 * 10^{-5}$ \\
\hline
\end{tabular}

Table 2. Correlations to find out thermo-physical properties of $\mathrm{Fe}_{3} \mathrm{O}_{4}$ nanofluid

\begin{tabular}{|c|c|}
\hline Density[7] & $\rho_{M N F}=(1-\phi) \rho_{F}+\phi \rho_{p}$ \\
\hline Specific Heat[7] & $C_{M N F}=(1-\phi) C_{F}+\phi C_{P}$ \\
\hline Viscosity[7] & $\mu_{M N F}=\mu_{F}\left(\frac{1}{(1+\phi)^{2.5}}\right)$ \\
\hline $\begin{array}{c}\text { Thermal } \\
\text { Expansion } \\
\text { Coefficient [8] }\end{array}$ & $\beta_{M N F}=\left(\frac{(1-\phi)(\rho \beta)_{F}}{\rho_{M N F}}\right)+\left(\frac{\phi(\rho \beta)_{P}}{\rho_{M N F}}\right)$ \\
\hline
\end{tabular}

For the same heat input, loop length, elevation between the heat source and tube diameter, temperature difference across heat source is given by

for laminar flow

$$
\frac{\Delta T_{M N F}}{\Delta T_{F}}=\left(\frac{\mu_{M N F}}{\mu_{F}}\right)^{1 / 3}\left(\frac{\rho_{F}}{\rho_{M N F}}\right)\left(\frac{c_{F}}{c_{M N F}}\right)^{2 / 3}\left(\frac{\beta_{F}}{\beta_{M N F}}\right)^{1 / 3}
$$

for turbulent flow

$$
\frac{\Delta T_{M N F}}{\Delta T_{F}}=\left(\frac{\mu_{M N F}}{\mu_{F}}\right)^{1 / 12}\left(\frac{\rho_{F}}{\rho_{M N F}}\right)^{3 / 4}\left(\frac{c_{F}}{c_{M N F}}\right)^{2 / 3}\left(\frac{\beta_{F}}{\beta_{M N F}}\right)^{1 / 3}
$$

\section{RESULTS AND DISCUSSION}

Figure 2 shows the variation of 'figure of merit' (newly defined term in eqn. (5) with \% of volume fraction of $\mathrm{Fe}_{3} \mathrm{O}_{4} /$ water MNF. It is to be noted that if water alone is used as working fluid in the FCL, figure of merit is $1.4521 \mathrm{E}-5$. By adding $1 \% \mathrm{~V} / \mathrm{V} \mathrm{Fe}_{3} \mathrm{O}_{4}$ particles to the base fluid, figure of merit has been decreased by $3.2 \%$. According to the eqns.5 and 6, figure of merit is directly proportional to the pressure drop and pumping power. Hence it can be concluded that, by replacing water with $\mathrm{MNF}$, pumping power requirement decreases. It is also noted from fig. 2 that, as $\%$ of volume fraction is increasing, figure of merit is decreasing proportionately. It is observed that the thermo-physical properties of $\mathrm{Fe}_{3} \mathrm{O}_{4}$ /water $\mathrm{MNF}$ varies with the volume fraction. With the volume fraction, density increases where as specific heat decreases. However, increase in the density is substantiating other changes. Only pressure drop due to friction is considered in the present analysis, giving pumping power is proportional to the friction coefficient. Figure 3 depicts the increase in volumetric heat capacity with increase in volume fraction. Volumetric heat capacity increases by $3 \%$ to $12.5 \%$ with addition of $\mathrm{Fe}_{3} \mathrm{O}_{4}$ particles from $1 \%$ to $5 \%$, when compared to that of water. Volumetric heat capacity is the measure of heat transportation capability of the given loop for the same volume flow.

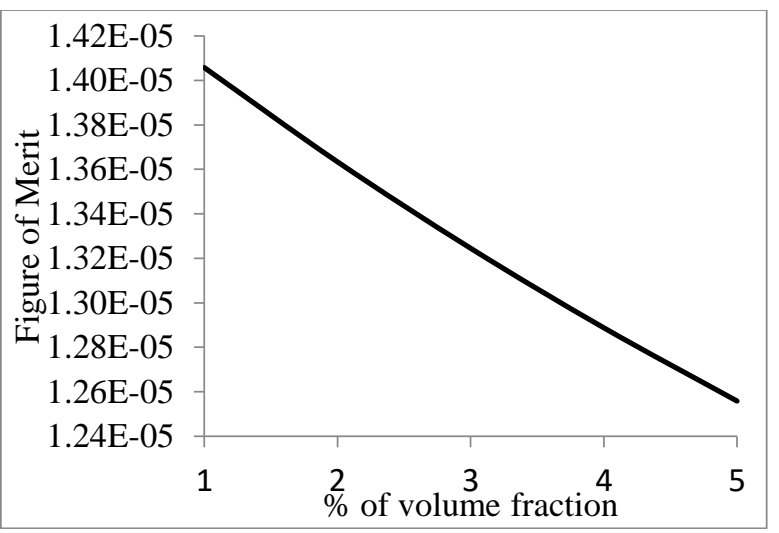

Figure 2. Variation of 'figure of merit' with $\% \mathrm{~V} / \mathrm{V}$

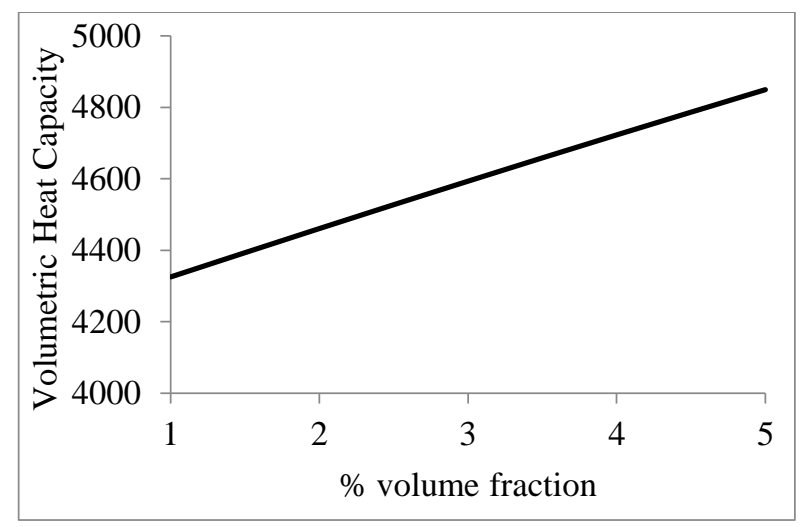

Figure 3. Variation of volumetric heat capacity with $\% \mathrm{~V} / \mathrm{V}$

Equation 8 has been derived in order to compare the different fluids which can be used in FCL. It can be observed from eqn. 8 that diameters ratio is the function of different thermo-physical properties. However, it is worth to note that influence of each property is not same. 


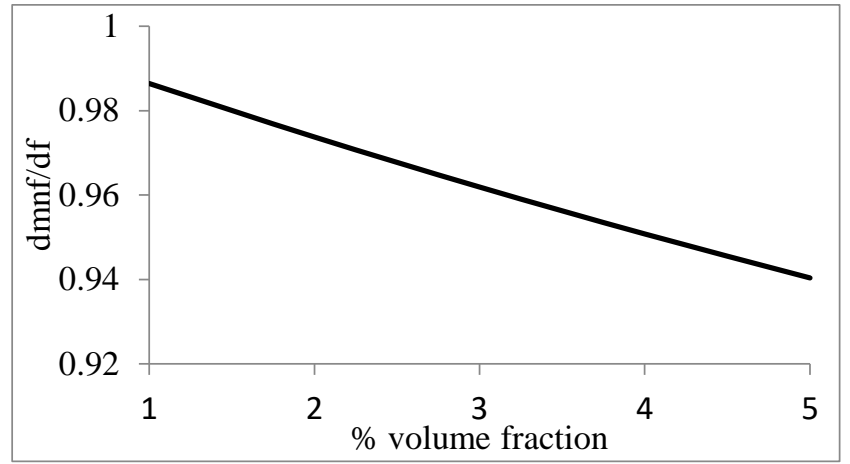

Figure 4. Variation of ratio of diameters with \%V/V (FCL)

Figure 4 shows the variation of diameters ratio with volume fraction. It is clear that, required diameter of the loop decreases with substitution of $\mathrm{Fe}_{3} \mathrm{O}_{4}$ /water MNF in place of water. It can be concluded that the compactness of the loop is marginally increasing with the volume fraction.

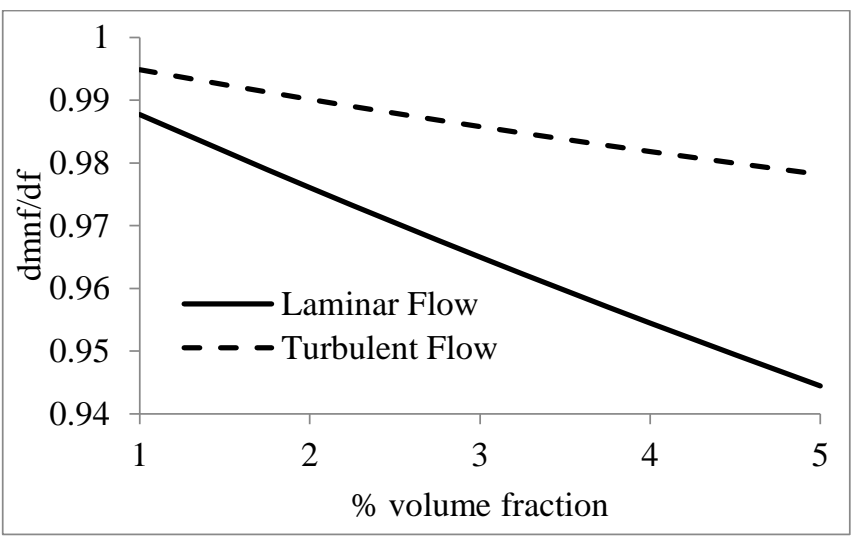

Figure 5. Variation of ratio of diameters with $\% \mathrm{~V} / \mathrm{V}$ (NCL)

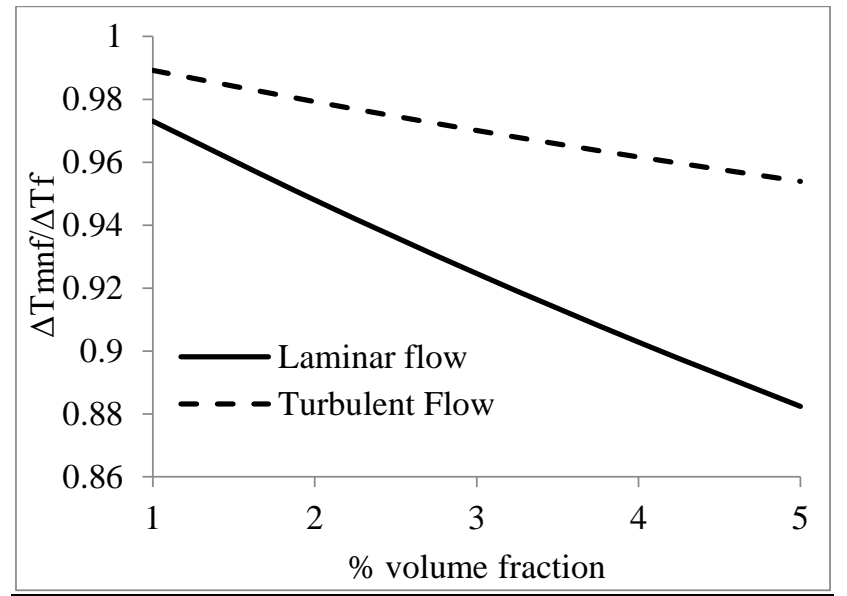

Figure 6. Variation of temperature drop across heat source with $\% \mathrm{~V} / \mathrm{V}(\mathrm{NCL})$

Figure 5 shows the variation of diameters ratio with volume fraction, for the loop working under natural circulation mode (NCL). From figure5 it can be observed different trends for laminar flow and turbulent flow. However, in both the cases, diameters ratio is decreasing with volume fraction. It is observed that from figure 4 and 5 that, decrease in diameters ratio is more in case of FCL compared with the NCL. This is because, thermal expansion coefficient plays a vital role in the case of natural circulation mode of operation.
In order to minimize the entropy generation, it is always preferable to operate the heat transfer loop in such a way that the temperature drop of the loop fluid across the heat source is as minimum as possible. Figure 6 explicit the temperature drops across the heat source for laminar flow and turbulent flows separately. It is worth to mention that, these results are drawn for the same heat input and loop length. It is seen that, temperature difference across heat source is decreasing with volume fraction.

\subsection{Effect of magnetic field}

To study the effect of magnetic field on the thermal conductivity, experiments are conducted by varying the magnetic field upto $500 \mathrm{G}$ with the step size of $50 \mathrm{G}$. Thermal conductivity is measured by KD2 probe. Thermal conductivity is measured for upto $5 \% \mathrm{~V} / \mathrm{V}$ concentration of the $\mathrm{Fe}_{3} \mathrm{O}_{4} /$ water nanofluid, at different magnetic field strengths. It is observed that, thermal conductivity of $\mathrm{Fe}_{3} \mathrm{O}_{4} /$ water MNF is increasing with magnetic field. It is to be noted that, at the absence of magnetic field, the thermal energy is greater than the magnetic dipolar attraction and the particles are moved under effect of the Brownian motion. Due to the dominant magnetic dipolar interaction energy, magnetic nanoparticles aggregate to form chainlike in the direction of the external magnetic field. Due to this chainlike structure, heat can be moved rapidly by solid particles. Consequently, enhanced the thermal conductivity of the $\mathrm{Fe}_{3} \mathrm{O}_{4} /$ water MNF is anticipated.

Experiments are repeated to ensure the repeatability. A new empirical correlation has been proposed based on the experimental results. Correlation coefficient value is 0.96 .

$$
\frac{k_{M N F}}{k_{f}}=1.1(1+\phi)^{2.4} B^{0.0182}
$$

where $\varphi$ is the volume fraction and B is the applied magnetic field in Gauss.

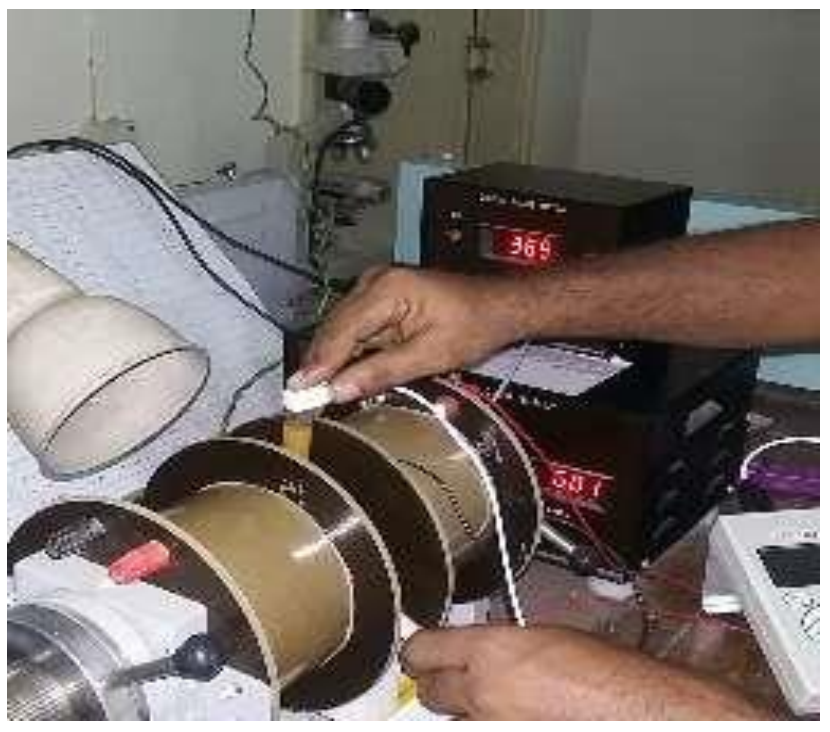

Figure 7. Thermal conductivity measurement 


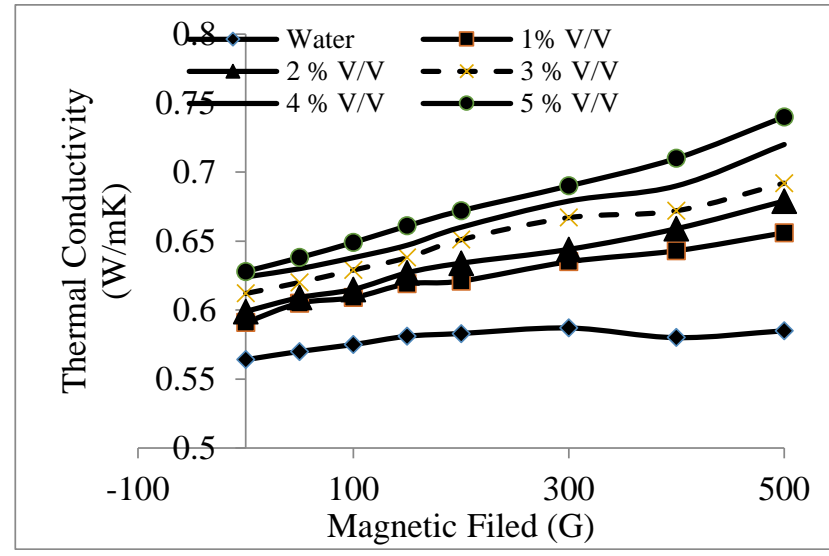

Figure 8. Variation of thermal conductivity

Viscosity can be calculated from the correlation proposed by Mohammad Amani et al [9].

$$
\frac{\mu_{M N F}}{\mu_{f}}=0.454(1+\phi)^{8.626} T^{-0.030} B^{0.592}
$$

Magnetic number is a non-dimensionless number which gives the effect of magnetic field strength on heat transfer characteristics [10]. It is worth to note that, as magnetic field strength increases, Magnetic number also increases. Few studies are available where correlations are proposed to find the Nusselt number in the presence of magnetic field [13]. As magnetic number increases, Nusselt number increases there by heat transfer coefficient increases. However, objective of the present paper is limited to give a quantitative picture on effect of magnetic nanofluid. In order to meet the objective, like done in the previous section, an analytical expression in terms of diameter ratio is proposed and analyzed.

$M n=\frac{B^{2} d^{2} 10^{-8}}{\sigma \rho \alpha^{2}}$

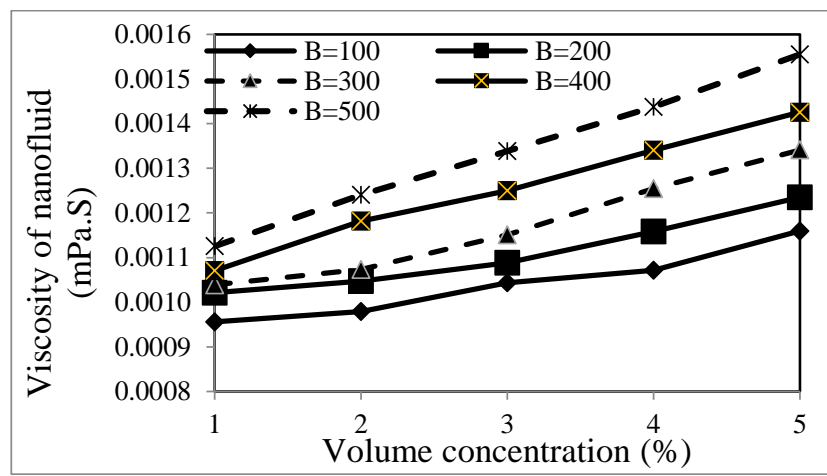

Figure 9. Variation of viscosity with respect to Concentration and Magnetic field strength

To compare chosen nanofluid with the base fluid, an analytical expression in terms of diameters ratio is derived. Keeping the Mn and B same, it can be shown that the ratio of the required diameter of the loop when MNF as working fluid to that with any other conventional fluid $\left(\mathrm{d}_{\mathrm{MNF}} / \mathrm{d}_{\mathrm{F}}\right)$ is given by:
$\frac{d_{M N F}}{d_{F}}=\left(\frac{\mu_{M N F}}{\mu_{F}}\right)\left(\frac{\rho_{F}}{\rho_{M N F}}\right)^{1 / 2}\left(\frac{c_{F}}{c_{M N F}}\right)\left(\frac{k_{F}}{k_{M N F}}\right)$

Thermal conductivity and viscosity of $\mathrm{Fe}_{3} \mathrm{O}_{4} /$ water nanofluid varies with magnetic field strength. Correlations given in equations 16 and 17 are used to predict these thermophysical properties.

From Fig. 10, it can be observed that, with increasing magnetic field strength, diameters ratio decreases for low concentration flows. This is due to the fact that, as magnetic field strength increases, both viscosity and thermal conductivity increases which can be evident from figures 8 and 9 respectively. It can be noticed from eqn.19 that viscosity and thermal conductivity influences the diameters ratio equally but inversely to each other. As nanofluid concentration increases, required diameters ratio decreases initially and after a certain value starts increasing. This may be attributed to the fact that, at high concentration, increase of viscosity is more compared to the thermal conductivity increase. At the same time, as magnetic field strength increases, viscosity as well as thermal conductivity increases. For example, at 5\% V/V, as field strength increases from 100 $\mathrm{G}$ to $500 \mathrm{G}$, viscosity increases from $0.00116 \mathrm{mPa}$.s to $0.00155 \mathrm{mPa}$.s which is $25.8 \%$ increase. At the same time, thermal conductivity increase is only $10 \%$. Whereas at $1 \%$ concentration, as field strength increases from $100 \mathrm{G}$ to 500 $\mathrm{G}$, viscosity increase is merely $12.6 \%$ whereas thermal conductivity increase is $16.4 \%$.

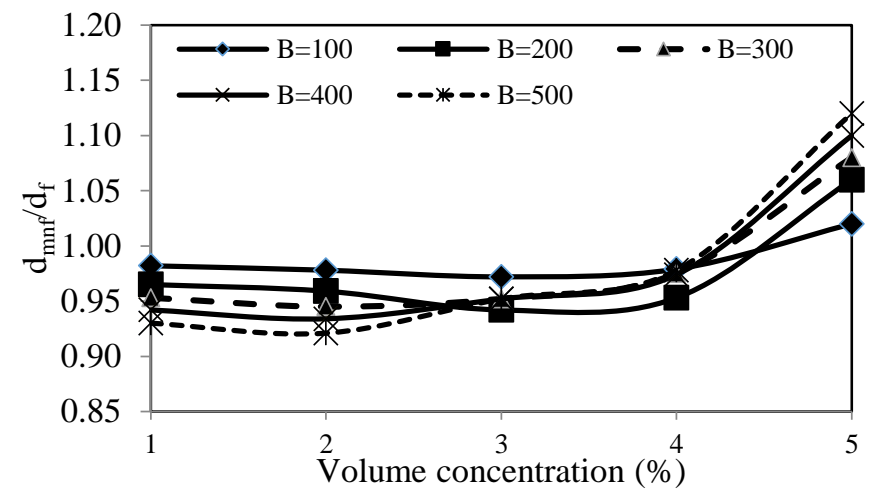

Figure 10. Variation of diameter ratio with respect to Concentration and Magnetic field strength

\section{CONCLUSIONS}

Comparison is made between water based heat transfer loops and $\mathrm{Fe}_{3} \mathrm{O}_{4} /$ water nanofluid (MNF) based heat transfer loops (for both forced circulation and natural circulation modes of operation). Separate analytical expressions for FCL and NCL are derived to calculate the size reduction of heat transfer loops. The great advantage of using MNF lies in the miniaturization of the required cooling loops. Another analytical expression is derived by considering external magnetic effect.

Following are the conclusions drawn:

1. $\mathrm{Fe}_{3} \mathrm{O}_{4}$ /water nanofluidis well suitable as working fluid in natural circulation as well as in forced circulation modes of heat transfer. 
2. For forced circulation loops, with nanofluid concentration 'figure of merit' decreases, consequently pressure drop decreases. It is also found that size of the loop is decreasing with volume fraction.

3. As magnetic field strength increases, thermal conductivity and viscosity of the $\mathrm{Fe}_{3} \mathrm{O}_{4}$ /water nanofluid increases. Increase of thermal conductivity and viscosity is more at higher concentrations.

4. Increase in the magnetic field strength decreases heat transfer loop diameter marginally at low concentrations and increases substantially at high concentrations.

\section{Scope of future work}

It is very clear from the present article that, $\mathrm{MNF}$ as working fluid in different heat transfer loops owes some benefits. However, knowledge on fluid flow behavior inside the loop is very critical. Hence, it is important to carryout numerical and experimental studies on both NCL and FCL, especially in the presence of magnetic field.

\section{ACKNOWLEDGMENT}

The present work is carried out under a project sponsored by UGC, GoI (MRP-6230/15/(SERO/UGC)). The financial support offered by UGC is gratefully acknowledged.

\section{REFERENCES}

[1] Nakayama W. (1986). Thermal management of electronic equipment: are view of technology and research topics. Appl. Mech. Rev. 39(12): 1847-1868.

[2] Melinder A. (2007). Choosing secondary working fluid for two common types of indirect system applications. International Congress of Refrigeration, Beijing.

[3] Nkurikiyimfur I, Wanga Y, Pan Z. (2013). Heat transfer enhancement by magnetic nanofluids-A review. Renewable and Sustainable Energy Reviews 21: 548561.

[4] Bahiraei M, Hangi M. (2015). Flow and heat transfer characteristics of magnetic nanofluids: A review. J MagnMagn Mater 374: 125-138.

[5] Zvirin Y. (1981). A review of natural circulation loops in pressurized water reactors and other systems. Nuclear Engineering and Design 67: 203-225.

[6] Kumar KK, Gopal MR. (2009). Carbon dioxide as secondary fluid in natural circulation loops. Proc. IMechE, Part E: J. Process Mech. Eng. 223: 189-194.

[7] Pak BC, Cho YI. (1998). Hydrodynamic and heat transfer study of dispersed fluids with submicron metallic oxide particles. Exp Heat Transfer 11: 151-70.

[8] Ghasemi B, Aminossadati SM, Raisi A. (2011). Magnetic field effect on natural convection in a nanofluid-filled square enclosure. International Journal of Thermal Sciences 50: 1748-1756.

[9] Mohammad A, et al. (2017). Experimental study on viscosity of spinel-type manganese ferrite nanofluid in attendance of magnetic field. Journal of Magnetism and Magnetic Materials 428: 457-463.
[10] Mohammad A, et al. (2017). Investigating the convection heat transfer of $\mathrm{Fe}_{3} \mathrm{O}_{4}$ nanofluid in a porous metal foam tube under constant magnetic field. Experimental Thermal and Fluid Science 82: 439-449.

[11] Nasrin et al. (2016). Comparative study between 2D and 3D modeling of nanofluid filled flat plate solar collector. International Journal of Heat and Technology 34 (3): 527-536. https://doi.org/10.18280/ijht.340326

[12] Ammar M, et al. (2017). Numerical study of nanofluid heat transfer $\mathrm{SiO}_{2}$ through a solar flat plate collector. International Journal of Heat and Technology 35(3): 619-625. https://doi.org/10.18280/ijht.350319

[13] Fazle M, et al. (2017). Radiation effects on Williamson nanofluid flow over a heated surface with magnetohydrodynamics. International Journal of Heat and Technology $35 \quad$ (1): $196-204$. https://doi.org/10.18280/ijht.350126

\section{NOMENCLATURE}

A Cross sectional Area of the pipe $\left(\mathrm{m}^{2}\right)$

B Magnetic field strength $(\mathrm{G})$

c Specific heat capacity $(\mathrm{kJ} / \mathrm{kg}-\mathrm{K})$

$\mathrm{d} \quad$ Diameter of the pipe (m)

$f_{c} \quad$ Friction factor

g Acceleration due to gravity $\left(\mathrm{m} / \mathrm{s}^{2}\right)$

$\mathrm{L}_{\mathrm{t}} \quad$ Total length (m)

Mn Magnetic number(-)

$\mathrm{m} \quad$ Mass flow rate $(\mathrm{kg} / \mathrm{s})$

Q Heat load (kW)

$\mathrm{u} \quad$ Fluid velocity $(\mathrm{m} / \mathrm{s})$

$\mathrm{k}$ Thermal Conductivity $(\mathrm{W} / \mathrm{mK})$

$\mathrm{V} \quad$ Volume flow rate $\left(\mathrm{m}^{3} / \mathrm{s}\right)$

$\Delta \mathrm{p} \quad$ Pressure drop $(\mathrm{kPa})$

$\mathrm{R} \quad$ Overall resistance parameter

$\Delta \mathrm{T} \quad$ Temperature difference across heat source $(\mathrm{K})$

\section{Greek symbols}

$\rho \quad$ Density $\left(\mathrm{kg} / \mathrm{m}^{3}\right)$

$\Phi \quad$ Volume Fraction

$\eta \quad$ Efficiency of the motor

$\alpha \quad$ Thermal Diffusivity $\left(\mathrm{m}^{2} / \mathrm{s}\right)$

$\sigma \quad$ Surface tension $(\mathrm{N} / \mathrm{m})$

$\beta \quad$ Thermal Expansion coefficient $\left(\mathrm{K}^{-1}\right)$

$\mu \quad$ Dynamic viscosity (Pa-s)

\section{Subscripts}

$\begin{array}{ll}\text { MNF } & \text { Magnetic Nanofluid } \\ \text { F } & \text { Base Fluid } \\ \text { p } & \text { Particle }\end{array}$

\section{Abbreviations}

NCL Natural Circulation Loop

FCL Forced Circulation Loop

MNF Magneticnanofluid 